\title{
An Insight into the Etiopathogenesis of Urinary Retention in Patients managed at a Tertiary Care Hospital in Amritsar, Punjab, India
}

\author{
${ }^{1}$ Darpan Bansal, ${ }^{2}$ Gurpreet S Bhangu, ${ }^{3}$ Ashish P Singh, ${ }^{4}$ Harpreet Singh, ${ }^{5}$ Noopur Bansal, ${ }^{6}$ Ritansh Bansal
}

\begin{abstract}
Introduction: Urinary retention is defined as the inability to urinate voluntarily. Acute urinary retention (AUR) is the sudden and painful inability to void, despite having a full bladder. Chronic urinary retention (CUR) is painless retention associated with an increased volume of residual urine. Despite the worldwide interest in the subject, there exist only a limited amount of data with respect to the causes of AUR and CUR. The main aim of study was to study the main aspects of causes and frequency of different causes of urinary retention with their age and incidence in this part of India.
\end{abstract}

Materials and methods: In this study, 100 patients presenting to the outpatient department (OPD) and emergency of a tertiary care hospital in Amritsar with urinary retention were evaluated and categorized into two groups: AUR and CUR. Further, these patients were subdivided into etiological classification according to the study.

Results: In men, benign prostatic enlargement is the leading cause of urinary retention, with second being stricture urethra. In women, urinary retention was mainly caused by meatal stenosis and blood clots due to urinary bladder growth. We also found some correlation of urinary retention with health negligence and less personal hygiene, which was more common in below-poverty-line patients.

Keywords: Acute retention, Chronic retention, Urinary retention.

How to cite this article: Bansal D, Bhangu GS, Singh AP, Singh H, Bansal N, Bansal R. An Insight into the Etiopathogenesis of Urinary Retention in Patients managed at a Tertiary Care Hospital in Amritsar, Punjab, India. Curr Trends Diagn Treat 2017;1(2):64-67

Source of support: Nil

Conflict of interest: None

\section{INTRODUCTION}

Urinary retention is defined as the inability to urinate voluntarily. Acute urinary retention is the sudden and

\footnotetext{
${ }^{1,2}$ Associate Professor, ${ }^{3-6}$ Junior Resident

${ }^{1-6}$ Department of Surgery, Sri Guru Ram Das Institute of Medical Sciences \& Research, Amritsar, Punjab, India
}

Corresponding Author: Darpan Bansal, Associate Professor Department of Surgery, Sri Guru Ram Das Institute of Medical Sciences \& Research, Amritsar, Punjab, India, e-mail: bhatiadarpan27@gmail.com painful inability to void, despite having a full bladder. ${ }^{1}$ Etiology of acute retention of urine is varied and extends from mechanical obstruction to neurological lesion or even without any actual demonstrative lesion, i.e., functional. From a clinical and prognostic point of view, spontaneous AUR should be separated from precipitated AUR. Importance of differentiating the two types of AUR becomes clear when evaluating the ultimate outcomes of patients. After spontaneous AUR, $15 \%$ of patients had another episode of spontaneous AUR and a total of $75 \%$ underwent surgery, whereas after precipitated AUR only $9 \%$ had an episode of spontaneous AUR, and $26 \%$ underwent surgery.

Chronic urinary retention is painless retention associated with an increased volume of residual urine. ${ }^{2}$ Patients with CUR can present with complete lack of voiding, incomplete bladder emptying, and overflow incontinence. Patients may be asymptomatic or present with lower urinary tract symptoms, related to storage and voiding difficulties.

Urinary retention in men becomes more common with age. In men aged 40 to 83 years, the overall incidence of urinary retention is 4.5 to 6.8 per 1,000 men. ${ }^{3}$ Although it is largely a condition that affects men, still there is an appreciable background incidence in women. Urinary retention in women is less common, though not rare. ${ }^{4}$ The cause of urinary retention in women is unknown in about one-third of cases but approximately half are due to Fowler's syndrome (typically seen in women in their twenties to thirties and thought to be due to failure of the urethral sphincter to relax appropriately). ${ }^{5}$

Despite the worldwide interest in the subject, there exist only a limited amount of data with respect to the causes of AUR and CUR. The main focus of our study was to identify different causes of retention of urine, their frequency, as well as their correlation with age and sex.

\section{MATERIALS AND METHODS}

This study was conducted at Sri Guru Ram Das Institute of Medical Sciences \& Research, Amritsar, Punjab, India from 2014 to 2017. Hundred patients of age group 15 to 75 years, presenting with urinary retention in surgical 
OPD and emergency were included in the study. These patients had either postvoid residual (PVR) urine more than $300 \mathrm{~mL}$ and / or were unable to urinate with palpable bladder with or without pain in abdomen. Informed written consent was taken from all patients. All patients were subjected to detailed history taking and general physical examination. All postoperative patients, previously diagnosed cases of retention already on treatment, patients with neurogenic bladder, and those who did not give consent were excluded from the study.

All the above patients were evaluated with required investigations like complete blood count, blood urea, and serum creatinine; urine complete and urine culture sensitivity; ultrasound abdomen; plain X-ray kidney, ureter, and bladder; uroflowmetry; retrograde urethrogram and micturating cystourethrogram; prostatespecific antigen; prostate biopsy; computed tomography abdomen and pelvis; magnetic resonance imaging spine and brain.

The patients fitting the above criteria were categorized into two groups: AUR and CUR. Further these patients were subdivided into etiological classification according to the study. The main aim of study was to study the primary aspects of causes and correlation of frequency of different causes of urinary retention with their age and incidence.

\section{Statistical Analysis}

Chi-square test was used for the qualitative data.

\section{RESULTS}

\section{Age Distribution in Years}

In our study, $79 \%$ of the patients were in age group of 55 to 74 years with $21 \%$ falling in age limit of 15 to 54 years.

\section{Sex Distribution}

Out of the 100 patients, 97 patients were males. However, there was not any selection bias.

\section{Correlation of Retention with Socioeconomic Status}

In this study, $74 \%$ were socioeconomically well off, while $26 \%$ were below poverty line.

\section{Type of Population}

According to Punjab census 2011, 62\% of total population is rural in Punjab. As per less medical facilities provided in rural areas, below-poverty-line population is more in rural regions of Punjab, and less personal care of rural population could be the reason for rural areas being more prone to urinary retention. In our study, rural to urban ratio of population presenting with retention was 3:1.

\section{Type of Urinary Retention}

About $53 \%$ of our patients presented with CUR, while only $47 \%$ suffered from acute retention.

As shown in Table 1, out of total 47 patients with AUR, only 1 patient had spontaneous AUR, other 46 had precipitated AUR. Precipitated AUR refers to the inability to urinate after a triggering event, such as nonprostaterelated surgery, anesthesia, and ingestion of medications with sympathomimetic or anticholinergic effects. All other AUR episodes are classified as spontaneous.

In our study, 1 patient of 35 years had no history of previous retention episodes, no history of medication, no history of per-urethral surgery, presented with an episode of AUR which was relieved by single-time bladder decompression by k-90 with PVR of $350 \mathrm{~mL}$, and later patient voided without any difficulty. In this case, no alpha blocker was given and ultrasound showed $27 \mathrm{~cm}^{3}$ prostate with no back-pressure changes. This case was suspected spontaneous AUR.

\section{Etiological Study Analysis}

As shown in Graph 1 and Table 2, benign hypertrophy prostrate was the main cause of retention of urine with $34 \%$ of patients suffering from it, closely followed by patients of stricture urethra $(24 \%)$ and cancer prostrate (21\%), and spontaneous AUR with the least common cause of urinary retention (1\%).

Table 1: Types of acute retention patients in study population

\begin{tabular}{ll}
\hline Type of acute urinary retention & Number of patients \\
\hline Precipitated AUR & 46 \\
Spontaneous AUR & 1 \\
\hline Total & 47
\end{tabular}

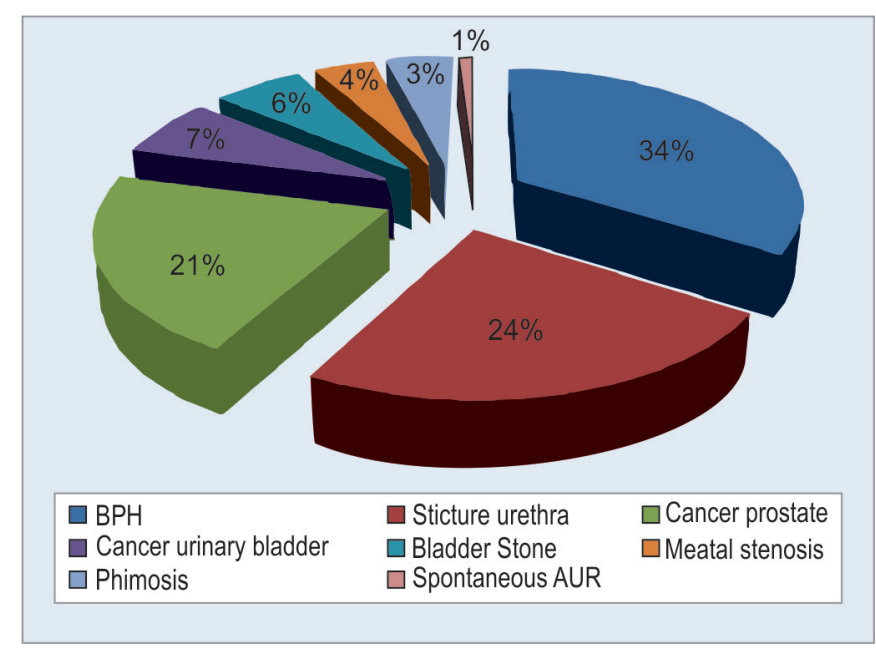

Graph 1: Etiological study (pie chart) of urinary retention patients 
Table 2: Number of acute urinary retention and CUR in study population along with mean age of all causes

\begin{tabular}{lllll}
\hline & $\begin{array}{l}\text { Acute } \\
\text { retention } \\
\text { (number of } \\
\text { patients) }\end{array}$ & $\begin{array}{l}\text { Chronic } \\
\text { retention } \\
\text { (number of } \\
\text { patients) }\end{array}$ & $\begin{array}{l}n=100 \\
\text { Total \% }\end{array}$ & $\begin{array}{l}\text { Mean age } \\
\text { (years) }\end{array}$ \\
\hline $\begin{array}{l}\text { Etiology } \\
\text { hyperplasia }\end{array}$ & 19 & 15 & 34 & 63.4 \\
$\begin{array}{l}\text { Stricture urethra } \\
\text { Cancer prostate }\end{array}$ & 5 & 19 & 24 & 52.0 \\
$\begin{array}{l}\text { Bladder stone } \\
\text { Meatal stenosis }\end{array}$ & 6 & 19 & 21 & 66.0 \\
$\begin{array}{l}\text { Phimosis } \\
\text { Spontaneous }\end{array}$ & 3 & 0 & 6 & 57.5 \\
AUR & 1 & 0 & 4 & 55.2 \\
Urinary bladder & 7 & 0 & 3 & 31.6 \\
growth & & 0 & 1 & 18.0 \\
\hline
\end{tabular}

\section{DISCUSSION}

Despite the worldwide interest in the subject there exists only a limited amount of data with respect to the incidence and causes of AUR and CUR. Incidence of primary AUR in western world is approximately 3/1000 per annum. ${ }^{6}$

In the present study, etiology has been critically analyzed, discussed, and compared with modern series. Although it has not been possible to discuss all the causes from very many angles, an attempt was made to discuss the important aspects of the various causes found in the present study.

The most common obstructive cause of retention is benign prostatic hyperplasia (BPH). ${ }^{1}$ In a study of 310 men over a 2-year period, urinary retention was caused by $\mathrm{BPH}$ in $53 \%$ of patients and other obstructive causes accounted for $23 \%{ }^{7}$ Murray et $\mathrm{al}^{8}$ concluded that BPH is the cause for the AUR in at least $65 \%$ of men presenting with AUR. In our study, BPH is cause for AUR in 36.1\% of men presenting with AUR.

European and American data showed the cancer prostate patients with AUR to be between 7.0 and 13.3\% ${ }^{9}$ It can therefore be said that prostate carcinoma is a wellknown and important cause of AUR. In our study, the cancer prostate patients presented with AUR were 6.0\% of the study population.

Other causes of AUR among men in our study were bladder calculi and phimosis. In the literature, bladder calculi have been reported to be a cause of AUR in 0.2 to $2 \%$ of cases. ${ }^{10,11}$ In our study, bladder calculi were the cause of AUR in $6.0 \%$ of all retention patients, and phimosis was the cause of AUR in $4.0 \%$ of all retention patients.

In our study, three females presented with retention among which two presented with meatal stenosis and one presented with retention due to clots of bladder carcinoma. Another study by Klarskov et $\mathrm{al}^{12}$ estimated that female AUR occurs 1 in 100,000 every year, and female-to-male incidence rate is 1:13, with postpartum and postoperative as the most common surgical causes of urinary retention.

Chronic urinary retention is a painless retention of urine associated with a significant PVR volume. ${ }^{13}$ Abrams et $\mathrm{al}^{13}$ assigned an arbitrary figure of $300 \mathrm{~mL}$ of residual urine after voiding as the minimum volume required for the definition of CUR. ${ }^{14}$ Some investigators defined CUR as PVR urine of more than $400 \mathrm{~mL},{ }^{15}$ or a postvoid volume of 100 to $500 \mathrm{~mL} ;{ }_{i}^{16}$ others have not given it a definite volume. In our study, CUR was found in about $52 \%$ of the patients. These patients had renal insufficiency confirmed by the presence of elevated serum creatinine levels.

\section{CONCLUSION}

Our study highlighted that urinary retention is not uncommon. Men were affected more frequently than women. In men, the leading cause of urinary retention is benign prostatic enlargement with second common being stricture urethra. In our study, carcinoma of the prostate has also come out to be an important cause of urinary retention. In female patients, urinary retention was mainly caused by meatal stenosis and blood clots due to urinary bladder growth. Initial and definitive management varied depending on the causes, gender, and age. We found some correlation of urinary retention with health negligence and less personal hygiene, which was more common in low socioeconomic group.

\section{REFERENCES}

1. Rosenstein D, McAninch JW. Urologic emergencies. Med Clin North Am 2004 Mar;88(2):495-518.

2. Hastie KJ, Dickinson AJ, Ahmad R, Moisey CU. Acute retention of urine: is trial without catheter justified? J R Coll Surg Edinb 1990 Aug;35(4):225-227.

3. Selius BA, Subedi R. Urinary retention in adults: diagnosis and initial management. Am Fam Physician 2008 Mar;77(5):643-650.

4. Weiss RM. Physiology and pharmacology of the renal pelvis and ureter. In: Kavoussi LR, Partin AM, Novick AC, Peters CA, editors. Campbell-Walsh urology. 10th ed. Philadelphia (PA): Saunders; 2011. pp. 1769-1770.

5. Kavia RB, Datta SN, Dasgupta R, Elneil S, Fowler CJ. Urinary retention in women: its causes and management. BJU Int 2006 Feb;97(2):281-287.

6. Cathcart P, van der Meulen J, Armitage J, Emberton M. Incidence of primary and recurrent acute urinary retention between 1998 and 2003 in England. J Urol 2006 Jul;176(1): 200-204.

7. Elhilali M, Vallancien G, Emberton M, Harving N, van Moorselaar J, Matzkin H, Alcaraz A. Management of acute urinary retention in patients with $\mathrm{BPH}$ : a worldwide comparison. J Urol 2004;171(Suppl):407. 
8. Murray K, Massey A, Feneley RC. Acute urinary retention - a urodynamic assessment. Br J Urol 1984 Oct;56(5):468-473.

9. Moul JW, Davis R, Vaccaro JA, Sihelnik SA, Belville WD, McLeod DG. Acute urinary retention associated with prostatic carcinoma. J Urol 1989 Jun;141(6):1375-1377.

10. Choong S, Emberton M. Acute urinary retention. BJU Int 2000 Jan;85(2):186-201.

11. AUA Practice Guideline Committee. AUA guideline on the management of benign prostatic hyperplasia (2003). Chapter 1: diagnosis and treatment recommendations. J Urol 2003 Aug;170(2 Pt 1):530-547.

12. Klarskov P, Andersen JT, Asmussen CF, Brenøe J, Jensen SK, Jensen IL, Lund P, Schultz A, Vedel T. Acute urinary retention in women: a prospective study of 18 consecutive cases. Scand J Urol Nephrol 1987;21(1):29-31.
13. Abrams PH, Dunn M, George N. Urodynamic findings in chronic retention of urine and their relevance to results of surgery. Br Med J 1978 Nov;2(6147):1258-1260.

14. Sakakibara R, Hattori T, Yasuda K, Yamanishi T. Micturitional disturbance in acute disseminated encephalomyelitis (ADEM). J Auton Nerv Syst 1996 Sep;60(3):200-205.

15. Gallien P, Reymann JM, Amarenco G, Nicolas B, de Seze M, Bellissant E. Placebo controlled, randomised, double blind study of the effects of botulinum A toxin on detrusor sphincter dyssynergia in multiple sclerosis patients. J Neurol Neurosurg Psychiatry 2005 Dec;76(12):1670-1676.

16. Holtgrewe HL, Mebust WK, Dowd JB, Cockett AT, Peters PC, Proctor C. Transurethral prostatectomies: practical aspects of the dominant operation in American urology. J Urol 1989 Feb;141(2):248-253. 